\title{
Spatial Variability of Irrigated Corn Yield in Relation to Field Topography and Soil Chemical Characteristics
}

\author{
J. R. MARQUES DA SILVA \\ C. ALEXANDRE \\ jmsilva@uevora.pt \\ Dep. Engenharia Rural, Universidade de Évora, 7002-554, Évora, Portugal
}

\begin{abstract}
Corn yield, topography and soil characteristics were sampled on a 26 ha area of a centre pivot irrigated cropland. The aim of the study was to determine relationships between corn yield, field topography and soil characteristics. The study was carried out in the Alentejo region of Portugal. Corn yield was measured with a combine harvester fitted with a grain-flow sensor and positioned by means of the Global Positioning System (GPS). A grid-based digital elevation model (DEM) with 1-m resolution was constructed and several topographic attributes were calculated from the DEM: the local slope gradient $(S)$, profile curvature (Curv), specific catchments area (SCa), and a steady-state wetness index $(W)$. Yield and topographical attributes were computed for areas of radius 5, 10, 25 and $50 \mathrm{~m}$, being considered its maximum, minimum, range and average values. The soil was systematically sampled with a mechanical probe for a total of 109 soil profiles used for analysis of the following soil superficial $(<0.30 \mathrm{~m})$ characteristics: extractable phosphorous $\left(\mathrm{P}_{2} \mathrm{O}_{5}\right)$ and extractable potassium $\left(\mathrm{K}_{2} \mathrm{O}\right)$, soil $\mathrm{pH}$, cation exchange capacity (CEC) and exchangeable bases. With centre pivot irrigation systems, the Wave ${ }_{50}$ index was shown to be useful for the identification of field areas in which low corn yields may be due to lack of water. At the same time, SCa was found to be useful for the identification of field areas in which low yields are due to excess water and drainage problems. Higher positive correlation between $\mathrm{pH}, \mathrm{Ca}$ and Curv were observed; calcium concentration was found on the transition areas between flat surfaces to concave ones, while lower values were detected in convex and concave areas. Topographical indexes, namely Wave ${ }_{50}$, SCa and Curv, can be especially helpful in site-specific management for delineating areas where crop yields are more sensitive to extreme water conditions.
\end{abstract}

Keywords: soil characteristics, spatial variability, topography, yield

\section{Introduction}

Soil characteristics play an important role in crop growth and yield. Over complex terrains, soil forming factors and erosion do not act uniformly but vary with position. Intuitively, we do not expect soil properties to be independent of one another. We would expect that what is eroded from the higher landscape positions must move downhill and alter what is described at lower lying positions.

Several researchers have attempted to increase our understanding of the biophysical factors that limit crop yield (Lamb et al., 1997; Bakhsh et al., 2000; Braga, 2000), but most have encountered difficulties in the interpretation of the results of the studies carried out, either due to the lack of consistency of results 